\title{
Fabrication of CdS/H-TiO 2 Nanotube Arrays and Their Application for the Degradation of Methyl Orange in Aqueous Solutions
}

\author{
Xiaosong Zhou, ${ }^{1}$ Fei Yang, ${ }^{2}$ Bei Jin, ${ }^{1}$ Liuyong Chen, ${ }^{1}$ and Shanshan $\mathrm{Li}^{1}$ \\ ${ }^{1}$ School of Chemistry Science and Technology, and Institute of Physical Chemistry, Zhanjiang Normal University, 29 Cunjin Road, \\ Chikan District, Zhanjiang 524048, China \\ ${ }^{2}$ The State Key Laboratory of Resources and Environmental Information System, Institute of Geographic Sciences and \\ Natural Resources Research, Chinese Academy of Sciences, 11A Datun Road, Chaoyang District, Beijing 100101, China
}

Correspondence should be addressed to Fei Yang; yangfei@igsnrr.ac.cn

Received 9 April 2014; Accepted 26 April 2014; Published 14 May 2014

Academic Editor: Prashant Kumar

Copyright (C) 2014 Xiaosong Zhou et al. This is an open access article distributed under the Creative Commons Attribution License, which permits unrestricted use, distribution, and reproduction in any medium, provided the original work is properly cited.

The fabrication and characterization of heterogeneous structures based on $\mathrm{CdS}$ and self-doped $\mathrm{TiO}_{2}$ nanotube arrays $(\mathrm{H}$ TNTs) are reported for the first time. CdS was conformally deposited onto $\mathrm{TiO}_{2}$ nanotube arrays (TNTs) using a simple method of electrochemical atomic layer deposition. The as-prepared samples were characterized by scanning electron microscopy (SEM), X-ray photoelectron spectroscopy (XPS), UV-Vis diffusion reflection spectroscopy (UV-Vis DRS), and photoluminescence spectroscopy (PL) techniques. Compared with pure TNTs, CdS/H-TNTs exhibit enhanced photoelectrochemical properties and photocatalytic activity under visible light. Self-doping introduces oxygen vacancies and $\mathrm{Ti}^{3+}$ species, and the electrochemical deposition technique promotes the deposition of $\mathrm{CdS}$ onto $\mathrm{TiO}_{2}$ nanotube walls, forming a heterojunction compact structure and resulting in decrease in photocatalytic activity under visible light.

\section{Introduction}

Since Fujishima and Honda first reported the use of a singlecrystal $\mathrm{TiO}_{2}$ semiconductor photoanode for the photocatalytic decomposition of water [1], $\mathrm{TiO}_{2}$ photocatalysts have quickly attracted the worldwide attention of environmental and energy researchers. Because of its highly ordered structure, large surface area, high recovery and high recycle rate, capability for scale-up, and excellent controllability, $\mathrm{TiO}_{2}$ nanotube arrays are favorable structures for many applications. However, the large band gap of titania restricts its photocatalytic applications to the UV range. Efforts to shift the band gap of $\mathrm{TiO}_{2}$ while maintaining the material's excellent charge-transfer properties and photocorrosion stability have primarily focused on metal/nonmetal ion doping to induce a red shift in the band gap [2]. However, the doping of foreign ions such as those of transition metals involves the drawbacks of thermal instability, a higher probability of forming charge carrier recombination centers, and expensive synthesis protocols [3]. Therefore, extending the photoresponse of $\mathrm{TiO}_{2}$ NTs to the visible-light range and increasing the material's photocatalytic efficiency remain possible objectives of future research.

Recently, appealing approaches based on dopant-free, pure $\mathrm{TiO}_{2}$ phase have been proposed to overcome the abovementioned shortcomings. Naldoni et al. prepared black, selfdoped $\mathrm{TiO}_{2}$ nanoparticles with a band gap of $1.85 \mathrm{eV}$ through the high-pressure hydrogenation of crystalline $\mathrm{TiO}_{2}$ [4]. Tao et al. reported the surface of self-doped $\mathrm{Ti}^{3+}$ rutile $\mathrm{TiO}_{2}\{011\}$ by the oxidation of bulk Ti interstitials, yielding a material with a band gap of only $2.1 \mathrm{eV}$ [5]. Self-doping with $\mathrm{Ti}^{3+}$ bulk species has also been demonstrated [6]. In particular, Xing et al. developed "vacuum-activated $\mathrm{TiO}_{2}$ " via annealing $\mathrm{TiO}_{2}$ in a vacuum drying oven to obtain a brownish powder with improved visible-light photocatalytic activities [7]. 
Zhang et al. reported that the $\mathrm{Ti}^{3+}$ ions exist on $\mathrm{TiO}_{2}$ nanotubes' surfaces in the form of oxygen vacancy- $\mathrm{Ti}^{3+}$ pairs, leading to aggravated electron recombination in $\mathrm{TiO}_{2}$ nanotube-containing cells [8]. Samiee and Luo reported the annealing of $\mathrm{TiO}_{2}$ nanoparticles in various controlled atmospheres. The results suggest that the use of vacuum environments or the presence of hydrocarbon species during annealing is effective in enhancing the photocatalytic activity [9]. These pure $\mathrm{TiO}_{2}$ phase visible-light photocatalysts have shown band-gap narrowing mainly attributed to surface disorder [4] and point defects, such as oxygen vacancies [6] and Ti interstitials [10]. However, the fabrication of selfdoped materials remains a challenge.

Very recently, much active research has focused on the anchoring of narrow-band-gap semiconductor materials (such as CdS) to TNTs, rendering these oxides sensitive to visible light $[11,12]$. In the CdS/TNTs integrated system, CdS has a relatively small band gap and is thus capable of harvesting photons in the visible and near-infrared regions [13]. The use of CdS is shown to enhance the charge carrier separation process and consequently is expected to enhance the inactivation efficiency. Zhu et al. reported on CdS/TNTs coaxial heterogeneous structures. These coaxial heterogeneous structures show a fivefold enhancement in photoactivity relative to the photoactivity of pure $\mathrm{TiO}_{2} \mathrm{NTs}$ [14].

In this paper, we report the study of CdS-sensitized $\mathrm{H}$ TNTs photoelectrodes and their photocatalytic performance. It is shown that the CdS/H-TNTs heterojunction structures exhibit enhanced photoelectrochemical properties and photocatalytic activities.

\section{Experimental}

2.1. Synthesis of H-TNTs. TNTs were fabricated by a method described in our previous report [15]. In a typical procedure, a $2 \times 3 \mathrm{~cm}^{2}$ cleaned Ti sheet (99\%) with a thickness of $0.1 \mathrm{~mm}$ was used as an anode and $\mathrm{Ir} / \mathrm{Ta}$ alloy as a cathode. The electrolyte was an aqueous solution composed of 1,2,3propanetriol, $\mathrm{NH}_{4} \mathrm{~F}$ (1.0 wt.\%), and $\mathrm{H}_{2} \mathrm{O}$ (15 vol.\%). The anodizing voltage was varied from 0 to $25 \mathrm{~V}$ at a rate of $100 \mathrm{mV} \cdot \mathrm{S}^{-1}$ and was held at $25 \mathrm{~V}$ for $2 \mathrm{~h}$. The prepared TNTs were then annealed in a hydrogen atmosphere at $500^{\circ} \mathrm{C}$ for $4 \mathrm{~h}$ and quickly cooled to obtain H-TNTs. For comparison, TNTs were also annealed at $500^{\circ} \mathrm{C}$ in air for $4 \mathrm{~h}$.

2.2. Synthesis of CdS/H-TNTs. CdS deposition was carried out from a solution containing $0.005 \mathrm{M} \mathrm{Na}_{2} \mathrm{~S}\left(\mathrm{Na}_{2} \mathrm{~S} \cdot 9 \mathrm{H}_{2} \mathrm{O}\right)$, $0.01 \mathrm{M} \mathrm{CdSO}_{4}\left(\mathrm{CdSO}_{4} \cdot 8 / 3 \mathrm{H}_{2} \mathrm{O}\right)$, and $0.15 \mathrm{M} \mathrm{EDTA}{ }^{2-}$ $\left(\mathrm{C}_{10} \mathrm{H}_{14} \mathrm{O}_{8} \mathrm{~N}_{2} \mathrm{Na}_{2} \cdot 2 \mathrm{H}_{2} \mathrm{O}\right)$ at a $\mathrm{pH}$ level of 8.5 , which was adjusted with perchloric acid and ammonia. A Pt foil counter electrode and an $\mathrm{Ag} / \mathrm{AgCl}$ were used in the three-electrode system. Initial cyclic voltammetry experiments were carried out at a deposition potential of $-0.75 \mathrm{~V}$ (versus $\mathrm{Ag} / \mathrm{AgCl}$ ). The deposition time for CdS electrodeposition was $5 \mathrm{~h}$.

2.3. Characterization of As-Prepared Samples. X-ray diffraction (XRD) patterns were recorded on an X-ray diffractometer (D/max-IIIA, Japan) using Cu Ka radiation and operating at $30 \mathrm{kV} / 30 \mathrm{~mA}$ over an angle range of 10 to $80^{\circ}$. The surface morphology was examined using a scanning electron microscope (SEM) (LEO1530VP, LEO Company) operated at an acceleration voltage of $15 \mathrm{kV}$. UV-Vis light absorption spectra were obtained on a Hitachi UV-3010 spectrophotometer equipped with an integrating sphere assembly and using the diffuse reflection method and $\mathrm{BaSO}_{4}$ as a reference. Electron paramagnetic resonance spectroscopy (EPR) was performed on a Bruker A300 spectrometer instrument. The instrument settings were as follows: microwave frequency of $9.51 \mathrm{GHz}$; microwave power of $3.16 \mathrm{~mW}$; and modulation amplitude of $1 \mathrm{G}$ at $100 \mathrm{kHz}$.

2.4. Photoelectrochemical and Photocatalytic Tests of As-Prepared Samples. Photocurrent measurements were carried out in a standard electrode photoelectrochemical cell using an electrochemical workstation (CV-27, BAS). The as-prepared samples, platinum gauze, and $\mathrm{Ag} / \mathrm{AgCl}$ were used as working, counter, and reference electrodes, respectively. A sodium sulfate solution $(0.5 \mathrm{M})$ was used as the electrolyte. Photocurrent was generated using filtered light $\left(\lambda>400 \mathrm{~nm}, 150 \mathrm{~mW} / \mathrm{cm}^{2}\right)$ from a PLS-SXE300UV Xe lamp. The light/dark short-circuit photocurrent response under zero bias was recorded with an Agilent digital multimeter.

The photocatalytic activity was measured in a XPAII reactor. The samples $\left(8 \times 20 \mathrm{~mm}^{2}\right)$ were immersed in $10 \mathrm{~mL}$ quartz test tubes containing $4 \mathrm{~mL}$ of methyl orange (MO) $(10 \mathrm{mg} / \mathrm{L})$ in the dark for $1 \mathrm{~h}$ to achieve adsorption equilibrium before irradiation. Visible-light $(\lambda>400 \mathrm{~nm})$ photocatalytic experiments were then conducted for $120 \mathrm{~min}$. The remaining dye concentrations in the reaction solution were determined using the U3010 spectrophotometer. The entire decomposition process was conducted by sparging air at a flow rate of $10 \mathrm{~mL} / \mathrm{min}$.

The existence of ${ }^{\circ} \mathrm{OH}$ can be tested by the terephthalic acid $\left(\mathrm{C}_{8} \mathrm{H}_{6} \mathrm{O}_{4}, \mathrm{TA}\right)$ fluorescent method. It has been demonstrated that ${ }^{\circ} \mathrm{OH}$ can react with $\mathrm{TA}$ and generate luminescent $\mathrm{TAOH}$ according to the equation [16] ${ }^{\circ} \mathrm{OH}+\mathrm{TA} \rightarrow \mathrm{TAOH}$.

An $8 \times 20 \mathrm{~mm}^{2}$ sheet of as-prepared photocatalyst was added to $4 \mathrm{~mL}$ of a solution containing $10 \mathrm{mM} \mathrm{NaOH}$ and $3 \mathrm{mM}$ TA in a quartz reactor. Prior to photoreaction, the suspension was magnetically stirred in the dark for $1 \mathrm{~h}$ to ensure the establishment of an adsorption/desorption equilibrium. The photoreaction was carried out as the foregoing photocatalytic reaction under visible light without oxygen bubbled into the suspension. After 150 min of photoreaction, the fluorescence spectra of the resultant solution were measured on an Edinburgh F-900 fluorescence spectrophotometer using an excitation wavelength of $320 \mathrm{~nm}$.

\section{Results and Discussion}

3.1. SEM and XRD Analysis of CdS/H-TNTs. Figure 1 shows SEM images of the as-prepared samples. A top-view SEM image of pure TNTs is shown in Figure 1(a); it can be observed that the as-prepared samples are uniform and well-aligned nanotubes with an outer average diameter of $100 \mathrm{~nm}$ and a tube-wall thickness of approximately $15 \mathrm{~nm}$. Figure $1(\mathrm{~d})$ 


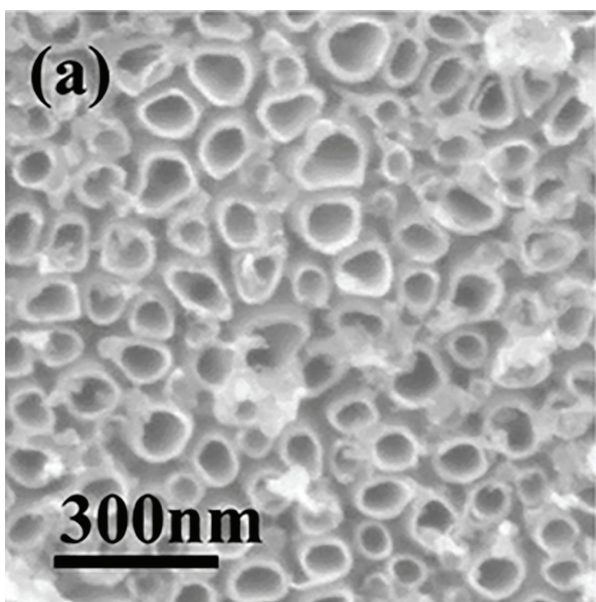

(a)

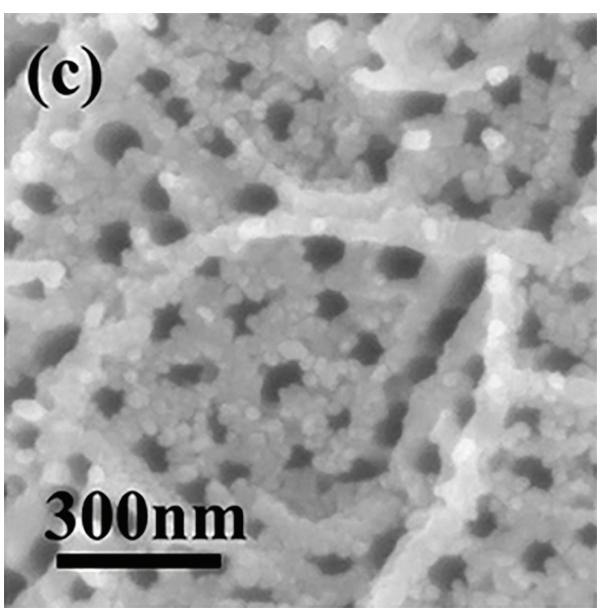

(c)

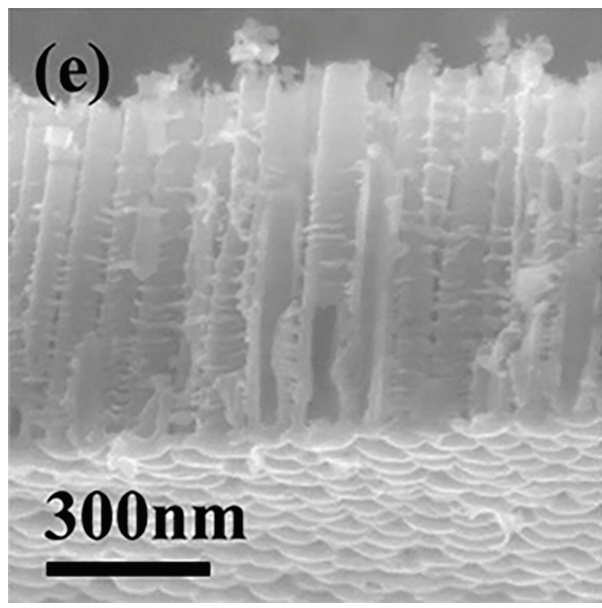

(e)

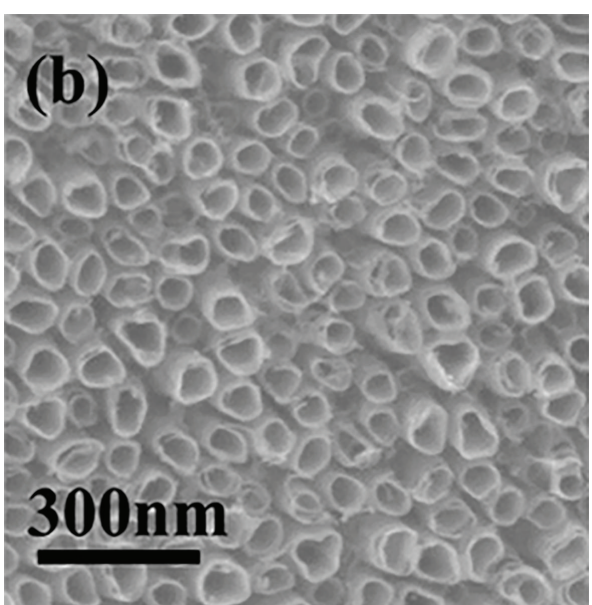

(b)

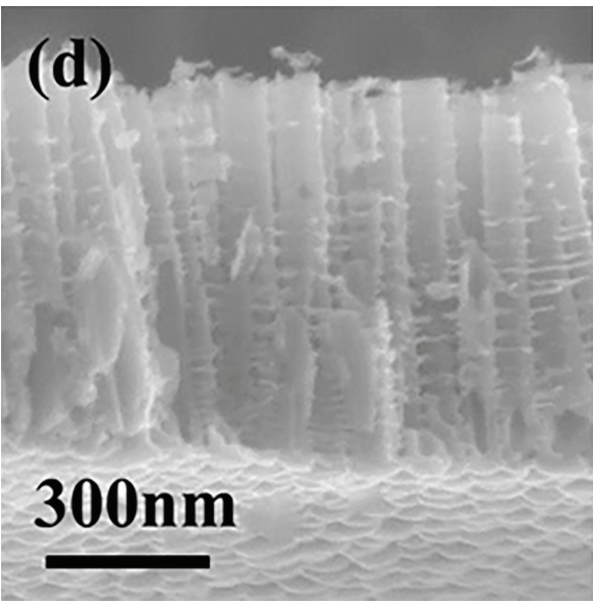

(d)

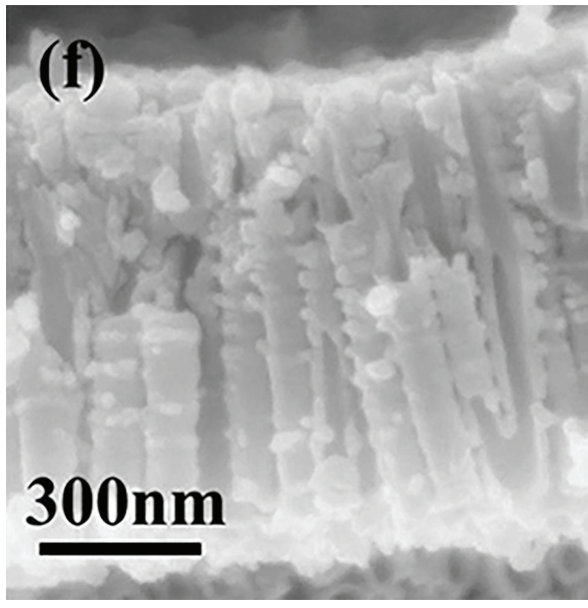

(f)

FIGURE 1: Morphologies of as-obtained samples: top-view SEM images of (a) pure TNTs, (b) H-TNTs, and (c) CdS/H-TNTs; side-view SEM images (d) TNTs, (e) H-TNTs, and (f) CdS/H-TNTs. 


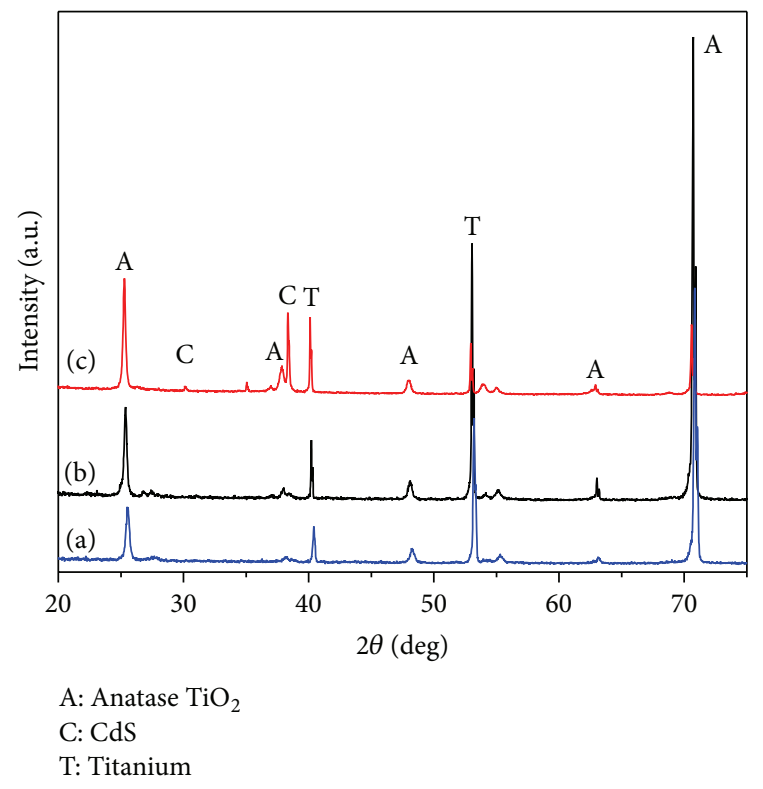

FIGURE 2: XRD patterns of as-synthesized samples: (a) TNTs, (b) HTNTs, and (c) CdS/H-TNTs.

show a side-view of pure TNT layers, which indicates that the layer thickness is approximately $800 \mathrm{~nm}$. Figures 1 (b) and $1(\mathrm{e})$ show face- and side-view SEM images of the $\mathrm{H}$ TNTs, respectively. The size and length of nanotubes were not significantly altered, which indicates that the hydrogen doped into the structures did not modify the morphology of the TNTs. However, many small particles on the face or inside of the nanotubes after CdS electrodeposition can be distinguished (shown in Figures 1(c) and 1(f)). The SEM images clearly show that $\mathrm{CdS}$ was successfully deposited onto the $\mathrm{TiO}_{2}$ nanotubes.

The XRD pattern of the as-prepared sample is shown in Figure 2. It is clear that the nanotubes consist of pure anatase $\mathrm{TiO}_{2}$ (JPCDS No. 21-1272) [17], and the peaks of Ti are derived from the Ti substrate. The peaks of the H-TNTs are the same as those of pure TNTs. These results suggest that the hydrogen doped into the TNTs has no effect on the nanotubes' crystal structure. Only the diffraction peaks of single-phase CdS and the $\mathrm{TiO}_{2}$ substrate, without the superfluous peaks of elemental Cd or S, were observed for the CdS/H-TNTs. The characteristic peaks of $\mathrm{CdS}$ are attributed to the cubic phase of CdS (JPCDS 80-0019) [12].

3.2. EPR and DRS Analysis of CdS/H-TNTs. The EPR spectra corresponding to the pure TNTs and H-TNTs at $77 \mathrm{~K}$ are shown in Figure 3; the species most likely responsible for these signals were assigned based only on reported $g$-tensor values. For pure TNTs, the values of $g_{1}, g_{2}$, and $g_{3}$ are 2.006, 2.005 , and 2.004, respectively, indicating the presence of a single adsorption site for the anion on the $\mathrm{TiO}_{2}$ surface after thermal treatment. The $g$-values of H-TNTs can be observed to fall between 1.985 and 1.999 , which is attributed to the $\mathrm{Ti}^{3+}$ species [18]. The results indicate a composite resonance

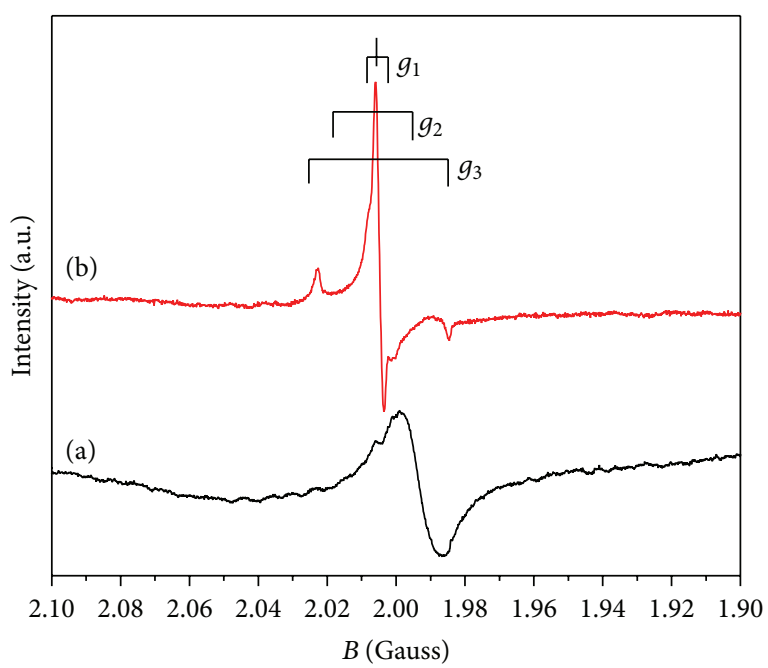

FIGURE 3: EPR spectra of as-prepared samples: (a) TNTs and (b) CdS/H-TNTs.

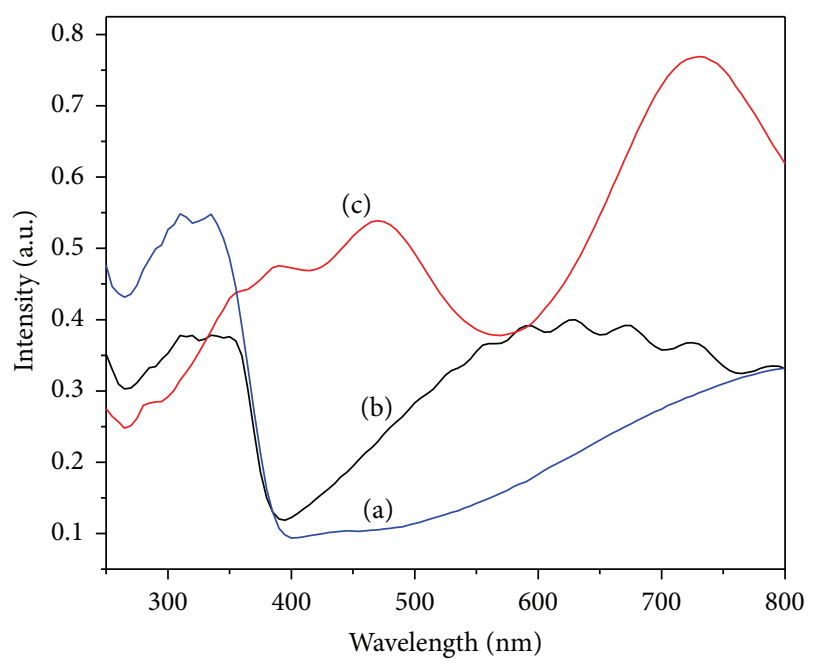

FIgURE 4: UV-vis absorption spectra of as-obtained samples: (a) TNTs, (b) H-TNTs, and (c) CdS/H-TNTs.

arising from both the surface and bulk $\mathrm{Ti}^{3+}$ centers after hydrogen reduction treatment.

Figure 4 presents the UV-visible diffuse reflectance spectra of the as-prepared samples. Compared with the spectra of the pure TNTs, the H-TNT spectra show strong visiblelight absorption from $400 \mathrm{~nm}$ to $700 \mathrm{~nm}$. However, there are two strong visible-light absorption peaks at 460 and $720 \mathrm{~nm}$, and significantly enhanced visible-light absorption by the CdS/H-TNTs can be inferred. These results suggest that hydrogen doping and CdS deposition can affect the UVvisible absorption of the samples.

3.3. Photocatalytic Activity. Figure 5 shows the photocatalytic activity exhibited by the as-obtained samples toward the decomposition of the organic pollutant MO under visiblelight irradiation. It is evident that the $\mathrm{CdS} / \mathrm{H}-\mathrm{TNT}$ s exhibited 


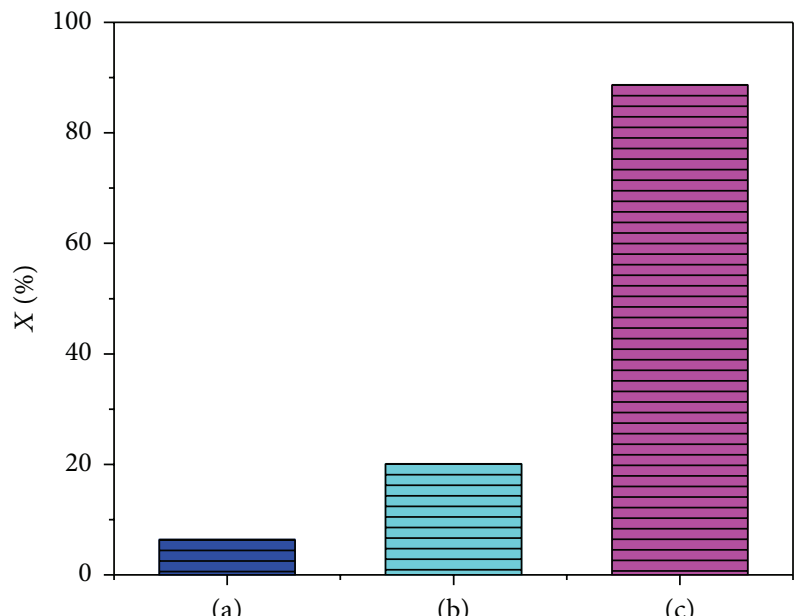

FIGURE 5: Photocatalytic activity of as-prepared samples: (a) TNTs, (b) H-TNTs, and (c) CdS/H-TNTs.

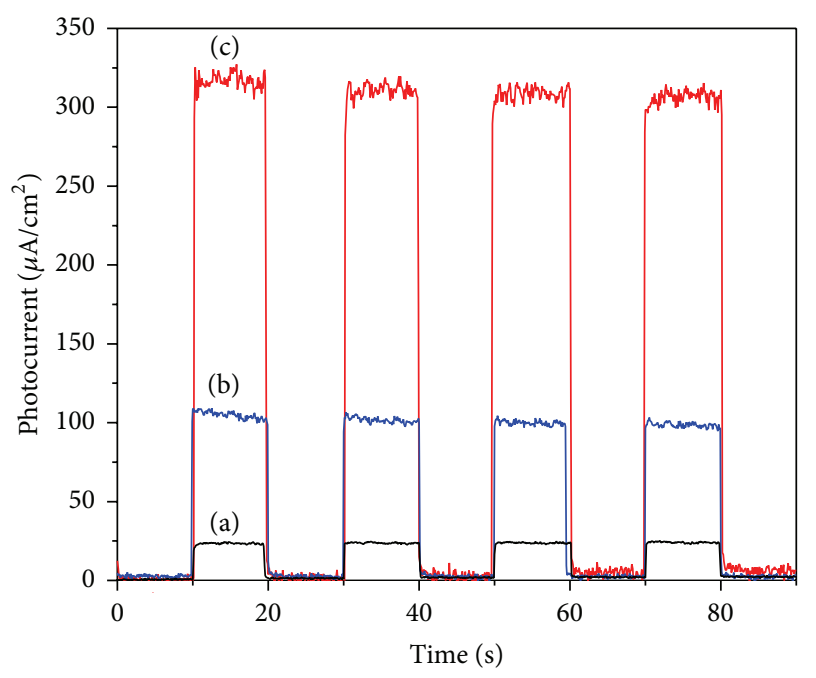

Figure 6: Photocurrent response of as-synthesized samples: (a) TNTs, (b) H-TNTs, and (c) CdS/H-TNTs.

much higher efficiency than the H-TNTs and pure TNTs. In particular, the decolorizing rate of the CdS/H-TNTs (88.7\%) was approximately 14 times that of the pure TNTs $(6.4 \%)$ and 4 times that of the H-TNTs (20.1\%) under visible-light irradiation.

The photocurrent responses of the as-prepared samples at a bias of $0 \mathrm{~V}$ versus $\mathrm{Ag} / \mathrm{AgCl}$ are shown in Figure 6. The CdS/H-TNTs exhibited superior performance with greater photocurrent generation efficiency compared to other samples. The photocurrent density of the $\mathrm{CdS} / \mathrm{H}-$ TNTs $\left(310 \mu \mathrm{A} \cdot \mathrm{cm}^{-2}\right)$ was 15 times that of the pure TNTs $\left(20 \mu \mathrm{A} \cdot \mathrm{cm}^{-2}\right)$. The higher photocurrent indicates that more photoinduced electrons could be transferred efficiently from the CdS/H-TNTs to the counter electrode via the external circuit under visible-light illumination. The photocatalytic

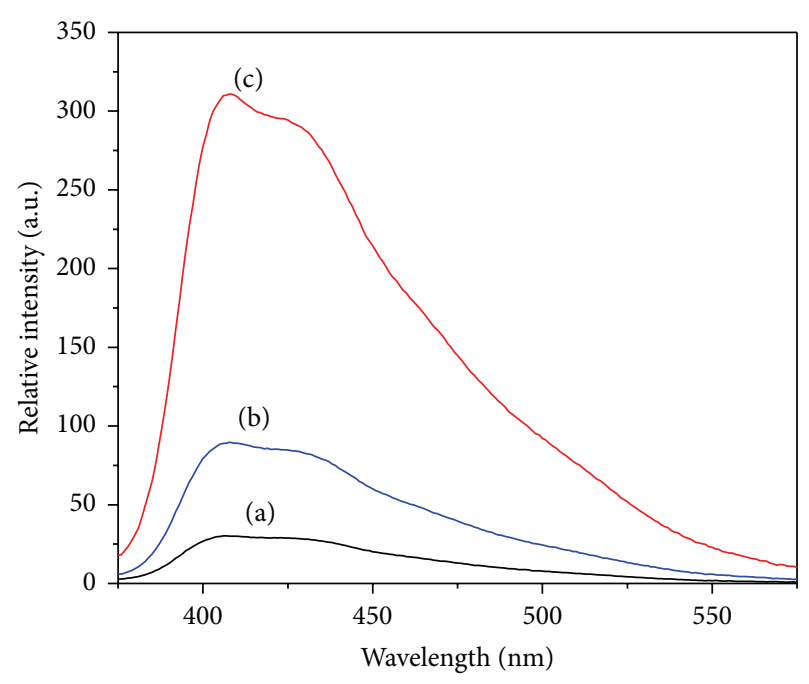

FIGURE 7: Fluorescence spectra recorded during visible-light illumination on samples in $10 \mathrm{mM} \mathrm{NaOH}$ and $3 \mathrm{mM}$ terephthalic acid solution (excitation at $320 \mathrm{~nm}$ ): (a) TNTs, (b) H-TNTs, and (c) CdS/H-TNTs.

activity of the catalyst greatly depended on the charge transfer of electron-holes, which is in good agreement with the higher photocatalytic activity observed for the $\mathrm{CdS} / \mathrm{H}$ TNTs compared with that of the pure TNTs.

It is well known that in the photooxidation reactions of organic molecules, the VB holes generated, or the main active species generated (such as ${ }^{\circ} \mathrm{OH}$ radicals) from the reaction of holes with surface-adsorbed water or hydroxyl groups can be directly utilized [16]. To qualitatively distinguish the involvement of holes and/or ${ }^{\circ} \mathrm{OH}$ radicals in the oxidation of MO, the prepared samples' capabilities for generating ${ }^{\circ} \mathrm{OH}$ radicals were compared by detecting the amount of 2-hydroxy terephthalic acid from the reaction of ${ }^{\circ} \mathrm{OH}$ radicals with terephthalic acid [19]. The CdS/H-TNTs showed approximately 13 times higher efficiency compared with the pure TNTs under visible-light irradiation (shown in Figure 7). This result indicates that the excellent capability of the $\mathrm{CdS} / \mathrm{H}$-TNTs for decomposing MO is probably caused by the direct involvement of photogenerated holes and electrons under visible-light illumination.

3.4. Photocatalytic Mechanism. The high efficiency achieved by the prepared samples may be attributed to two major improvements. First, oxygen vacancies and $\mathrm{Ti}^{3+}$ species created by self-doping cause the band gap of $\mathrm{TiO}_{2}$ to narrow (shown in Figure 8). Second, the electrochemical deposition technique promotes the deposition of CdS onto the $\mathrm{TiO}_{2}$ nanotube walls, forming a heterojunction compact structure that allows for the rapid and efficient transfer of photogenerated electrons from CdS to the Ti substrate; this charge transfer compares favorably with that of traditional mesoporous film electrodes, leading to greatly reduced electron-hole recombination and much improved photocurrent and efficiency. 


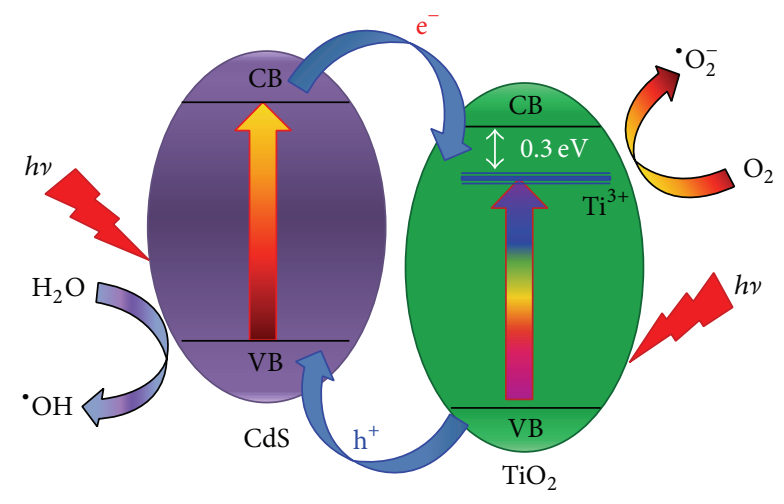

FIGURE 8: Schematic illustration of charge transfer and separation in $\mathrm{CdS}$ and H-TNTs under visible-light irradiation.

\section{Conclusion}

We have reported on the conceptual design and suitable architecture of a composite material formed from H-TNTs and the narrow-band-gap compound semiconductor CdS. The photocatalytic activity and photoelectrochemical performance of the CdS/H-TNTs were investigated. The CdS/HTNTs exhibited higher photocatalytic activity and photoelectrochemical performance than pure TNTs under visible light. This novel heterostructure architecture provides a promising way to develop effective devices for light energy conversion and wastewater treatment.

\section{Conflict of Interests}

The authors declare that there is no conflict of interests regarding the publication of this paper.

\section{Acknowledgments}

The authors thank the Guangdong Natural Science Foundation for a Grant provided through the Ph.D. Start-up Research Program (S2013040013755), Colleges and Universities in Guangdong Province Science and Technology Innovation Project (2013KJCX0123), Non-Funding Programs for Science and Technology Development of Zhanjiang (2013B01053), and Basic Works Project of Ministry of Science and Technology (2012FY111800-5).

\section{References}

[1] A. Fujishima and K. Honda, "Electrochemical photolysis of water at a semiconductor electrode," Nature, vol. 238, no. 5358, pp. 37-38, 1972.

[2] M. A. Khan and O. Yang, "Photocatalytic water splitting for hydrogen production under visible light on Ir and Co ionized titania nanotube," Catalysis Today, vol. 146, no. 1-2, pp. 177-182, 2009.

[3] W. Choi, A. Termin, and M. R. Hoffmann, "The role of metal ion dopants in quantum-sized $\mathrm{TiO}_{2}$ : correlation between photoreactivity and charge carrier recombination dynamics," Journal of Physical Chemistry, vol. 98, no. 51, pp. 13669-13679, 1994.
[4] A. Naldoni, M. Allieta, S. Santangelo et al., "Effect of nature and location of defects on bandgap narrowing in black $\mathrm{TiO}_{2}$ nanoparticle," Journal of the American Chemical Society, vol. 134, pp. 7600-7603, 2012.

[5] J. Tao, T. Luttrell, and M. Batzill, "A two-dimensional phase of $\mathrm{TiO}_{2}$ with a reduced bandgap," Nature Chemistry, vol. 3, pp. 296-300, 2011.

[6] F. Zuo, L. Wang, T. Wu, Z. Zhang, D. Borchardt, and P. Feng, "Self-doped $\mathrm{Ti}^{3+}$ enhanced photocatalyst for hydrogen production under visible light," Journal of the American Chemical Society, vol. 132, pp. 11856-11857, 2010.

[7] M. Xing, J. Zhang, F. Chen, and B. Tian, "An economic method to prepare vacuum activated photocatalysts with high photoactivities and photosensitivities," Chemical Communications, vol. 47, no. 17, pp. 4947-4949, 2011.

[8] X. B. Zhang, H. M. Tian, X. Y. Wang et al., "The role of oxygen vacancy- $\mathrm{Ti}^{3+}$ stateson $\mathrm{TiO}_{2}$ nanotubes' surface in dye-sensitized solar cells," Materials Letters, vol. 100, pp. 51-53, 2013.

[9] M. Samiee and J. Luo, "Enhancing the visible-light photocatalytic activity of $\mathrm{TiO}_{2}$ by heat treatments in reducing environments," Materials Letters, vol. 98, pp. 205-208, 2013.

[10] E. Lira, S. Wendt, P. Huo et al., "The importance of bulk $\mathrm{Ti}^{3+}$ defects in the oxygen chemistry on titania surfaces," Journal of the American Chemical Society, vol. 133, no. 17, pp. 6529-6532, 2011.

[11] S. Chen, M. Paulose, C. Ruan et al., "Electrochemically synthesized CdS nanoparticle-modified $\mathrm{TiO}_{2}$ nanotube-array photoelectrodes: preparation, characterization, and application to photoelectrochemical cells," Journal of Photochemistry and Photobiology A: Chemistry, vol. 177, no. 2-3, pp. 177-184, 2006.

[12] W. Sun, A. Yu, H. Pan, X. Gao, Q. Chen, and L. Peng, "CdS quantum dots sensitized $\mathrm{TiO}_{2}$ nanotube-array photoelectrodes," Journal of the American Chemical Society, vol. 130, no. 4, pp. 1124-1125, 2008.

[13] D. R. Baker and P. V. Kamat, "Photosensitization of $\mathrm{TiO}_{2}$ nanostructures with CdS quantum dots: particulate versus tubular support architectures," Advanced Functional Materials, vol. 19, no. 5, pp. 805-811, 2009.

[14] W. Zhu, X. Liu, H. Liu, D. Tong, J. Yang, and J. Peng, "Coaxial heterogeneous structure of $\mathrm{TiO}_{2}$ nanotube arrays with $\mathrm{CdS}$ as a superthin coating synthesized via modified electrochemical atomic layer deposition," Journal of the American Chemical Society, vol. 132, no. 36, pp. 12619-12626, 2010.

[15] X. Zhou, F. Peng, H. Wang, H. Yu, and J. Yang, "Preparation of $\mathrm{B}, \mathrm{N}$-codoped nanotube arrays and their enhanced visible light photoelectrochemical performances," Electrochemistry Communications, vol. 13, no. 2, pp. 121-124, 2011.

[16] T. Hirakawa and Y. Nosaka, "Properties of $\mathrm{O}_{2}{ }^{--}$and $\mathrm{OH}^{\bullet}$ formed in $\mathrm{TiO}_{2}$ aqueous suspensions by photocatalytic reaction and the influence of $\mathrm{H}_{2} \mathrm{O}_{2}$ and some ions," Langmuir, vol. 18, no. 8, pp. 3247-3254, 2002.

[17] X. Zhou, F. Peng, H. Wang, H. Yu, and Y. Fang, "A simple preparation of nitrogen doped titanium dioxide nanocrystals with exposed (001) facets with high visible light activity," Chemical Communications, vol. 48, no. 4, pp. 600-602, 2012.

[18] N. O. Gopal, H. Lo, and S. Ke, "Chemical state and environment of boron dopant in $\mathrm{B}, \mathrm{N}$-codoped anatase $\mathrm{TiO}_{2}$ nanoparticles: an avenue for probing diamagnetic dopants in $\mathrm{TiO}_{2}$ by electron paramagnetic resonance spectroscopy," Journal of the American Chemical Society, vol. 130, no. 9, pp. 2760-2761, 2008. 
[19] T. L. Thompson and J. J. T. Yates, "Surface science studies of the photoactivation of $\mathrm{TiO}_{2}$-new photochemical processes," Chemical Reviews, vol. 106, no. 10, pp. 4428-4453, 2006. 

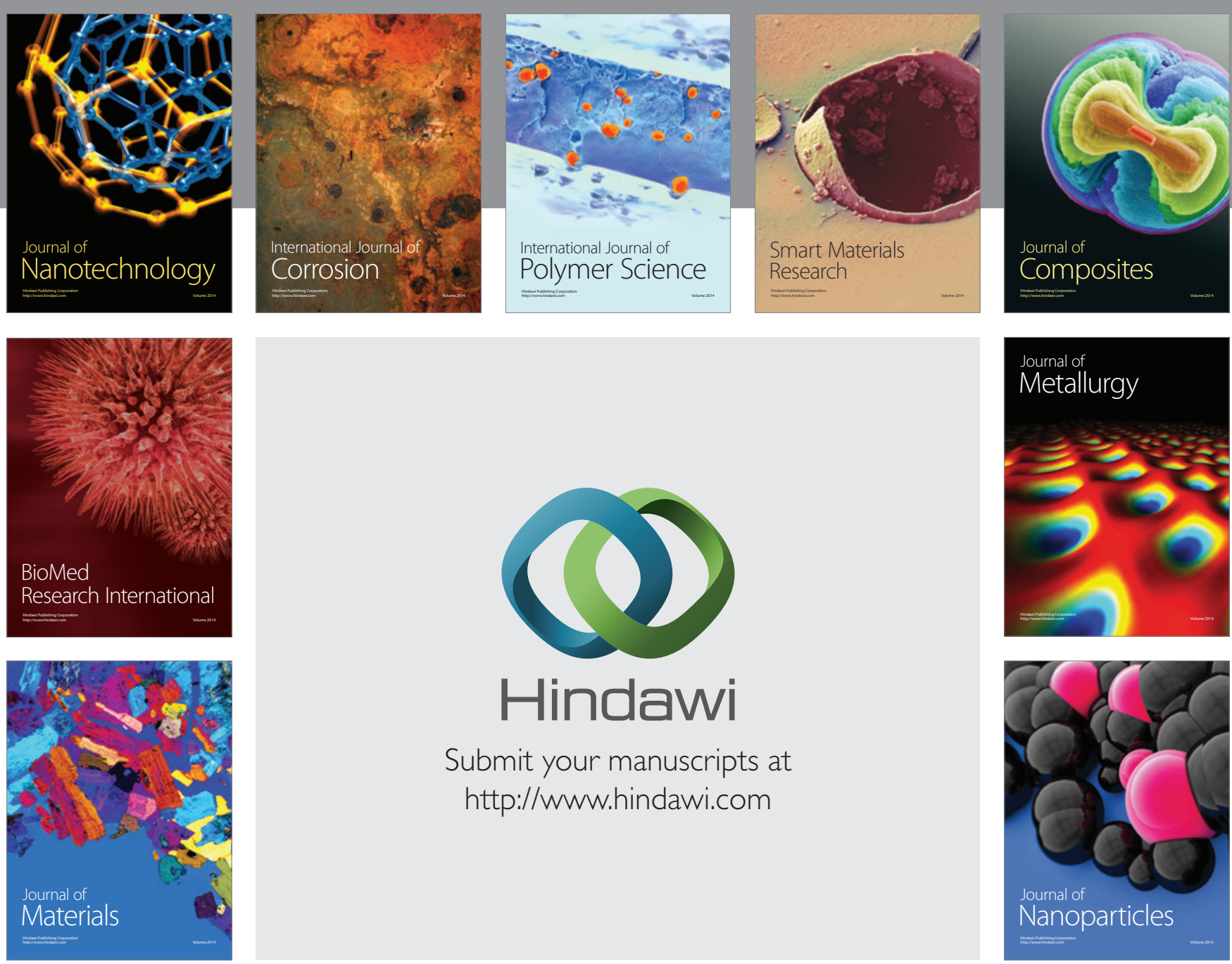

Submit your manuscripts at http://www.hindawi.com
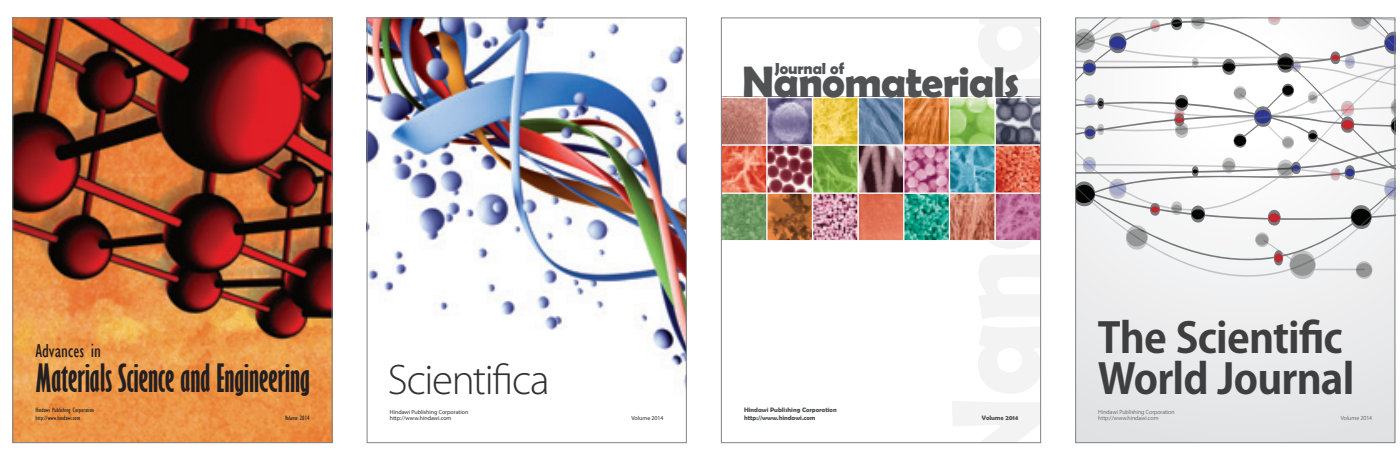

\section{The Scientific World Journal}
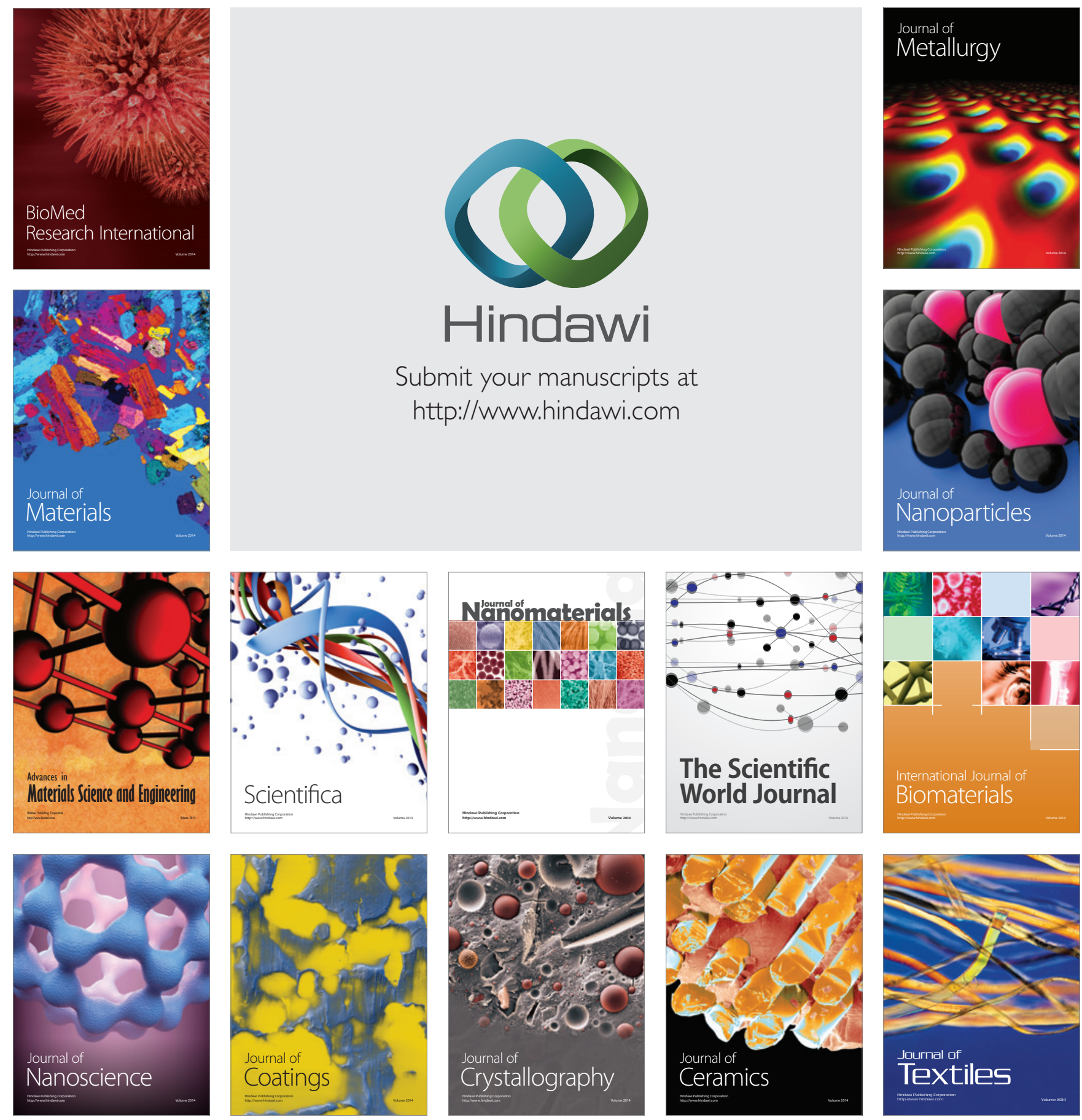